\title{
Improvisation of Security Arrangements for the Indian Railways: Novel Idea Employing Integration of UID and Smart Cards
}

\author{
Niladri P. Mohapatra ${ }^{1}$, Avipsa S. Panda ${ }^{2}$, Subhasmita Pradhan ${ }^{3}$ \\ Rajendra Prasad $^{4}$, G.L. Kumar Moganti ${ }^{5}$ \\ ${ }^{I}$ (School of Electronics, KIIT University, India) \\ ${ }^{2}$ (School of Electronics, KIIT University, India) \\ ${ }^{3}$ (School of Electronics, KIIT University, India) \\ ${ }^{4}$ (Asst. Prof., School of Electronics, KIIT University, India) \\ ${ }^{5}$ (Asst. Prof., School of Electronics, KIIT University, India)
}

\begin{abstract}
The paper brings forth a novel idea for intensification of the security system in the world's largest railway networks, Indian Railways. The design of smart cards has been proposed in the present paper which would play the role of Unique ID as well as passengers would be able to book their tickets via the card and even would be helpful in security checks. The paper also discusses the overall operation of the security arrangement and gives the rough diagrammatic picture of the setup.
\end{abstract}

Keywords: Indian railway, security systems, smart card, UID, UTS

\section{Introduction}

Indian Railways is one of the largest railway networks in the world. Aptly, the tagline of Indian Railways is "Lifeline of the Nation". Indian Railways started operation on April 16, 1853; 160 years ago. As of December 2012, statistics report that Indian railways transported over 25 million passengers daily (Wikipedia). With the rapid developing scenario all around, the Indian Railways has integrated Information Technology, in its working. Centre for Railway Information Systems (CRIS), the IT arm of the Indian Railways, set up in 1982, works in association with IT professionals and railway experts.

Yet, there are certain fall-outs in the Indian Railways, amidst which security is of prime concern. This paper proposes an idea which could be helpful for strengthening the security of the world's largest railway network. Section II deals with the existing security arrangements. Section III describes the proposed idea and Section IV brings the paper to a close.

\section{Background}

Security has been identified as one of the main concern for improvement. The crime graph for the railways is alarmingly high; be it incidents of sabotage, theft or harassment of women.

To discuss the prevailing security arrangements; there exists Railway Protection Force, which is responsible for security of railway assets and passengers. The 'Integrated Security Systems', comprising of multi-screening of passengers and their luggage as well as surveillance over passengers, is an approved idea by the Ministry of Railways, GOI, to be set up at important stations. [1]

All the more, the Indian Railways has already proposed a plan for hassle-free travelling of passengers, by introduction of 'Universal Tracking System' (UTS). "Under the proposed system, a chip based on a smart card system would be required to be used while undertaking journey by railways. The passengers would have to book their berths and seats in advance on the basis of the smart card system.” (Times of India, dated May13, 2012).

Nefarious activities may still take place; hence we can strengthen the security further.

\section{Proposed Idea}

We propose a security arrangement, involving integration of the UTS, the smart card (already established by the Indian Railways) with other security features.

The "Go-India" smart card, announced in the Indian Rail Budget 2011-12, can be used to book tickets at booking counters, automatic ticketing vending machines (ATVM) and also through the Internet.

"No physical ticket will be issued and the fare amount will be deducted from e-purse. Hand-held inspection devices will be there with the ticket checking staff, to check the validity of smart card and journey."

Now, coming to the proposition; the Smart card and the UTS would be put together as a single smart card. The proposed smart card would contain the biometric details (iris recognition, fingerprint), photo, and permanent address; apart from the basic details viz., Name, Gender, Blood Group and also would keep the details of the 
ticket. All the details would be saved globally (on a global database). [2] The card would be linked with a global bank, from which all the transactions would occur and the details would be saved in the database.

The ID mapper can be seen as a database which would have the Unique Identification Number, Account Number of Bank, Phone Number and Name of the individual. (Fig.1)

\begin{tabular}{|c|c|c|c|}
\hline \multicolumn{4}{|c|}{ ID Mapper } \\
\hline $\begin{array}{l}\text { Unique } \\
\text { Identificati } \\
\text { on No. }\end{array}$ & $\begin{array}{l}\text { Account } \\
\text { No. of } \\
\text { Bank }\end{array}$ & Name & Ph No. \\
\hline $\begin{array}{l}12344321 \\
1234\end{array}$ & $\begin{array}{l}10003456 \\
\text { YU }\end{array}$ & XYZ & $\begin{array}{l}9876543 \\
210\end{array}$ \\
\hline
\end{tabular}

Fig. 1: IP Mapper

The card can be used as an Identification proof, can be used to book tickets, as well as the card can be used for the validation of journey. The card should also facilitate PIN authentication of the user, to prevent fraudulent use by any other individual.

As per the proposed security arrangement, we propose manual check posts, with equipped security assets, Hand-held Metal Detectors (HHMD), Door-frame Metal detectors (DFMD) and baggage x-ray scanners; these are already prevalent in many stations. Next would be electronic check gates, where card readers would be installed, if the card has valid travel information, the gates would allow the passenger to pass.

For any person to enter the platform, he would have to go through the DFMD and HHMD, so that each person entering is scanned properly. Even for the issue of platform tickets, the smart card has to be used, so that the details each person entering the platform is present.

Even after passing the security checks, instances of ticket-less travelling or hijacking might take place. To avoid any such unforeseen incident, we propose card readers at the doors of each compartment and a camera for face recognition. The camera would match the photo in the card with the person. If all the details match, the door would open and the passenger would be allowed to enter the coach. In case of some mismatch, an alarm would ring, and then the manual help would come into picture.

A rough design of the proposal is shown in Fig. 2 and the outline of the overall operation is shown in Fig.3.

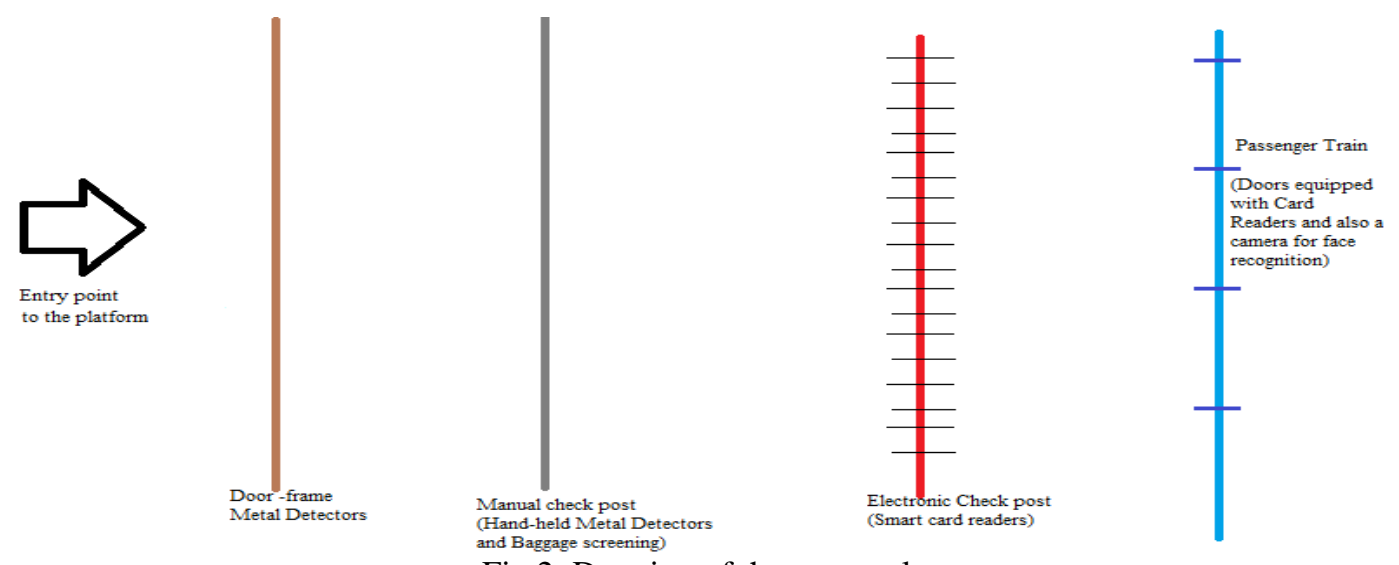

Fig.2: Drawing of the proposal 


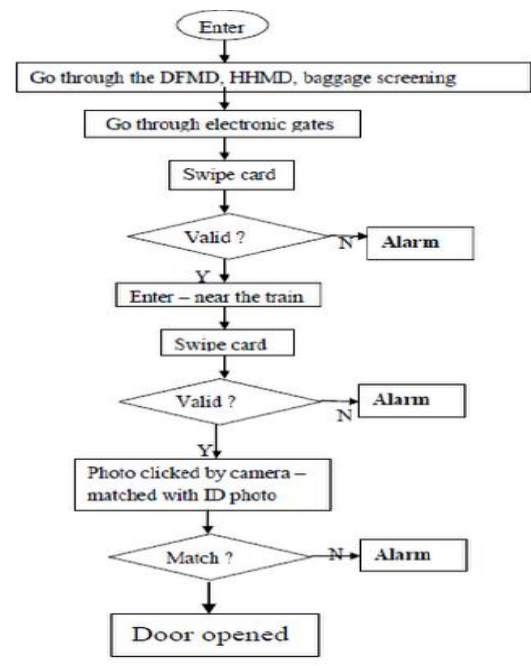

Fig. 3: Overall operation

\section{A. Hardware Aspects}

The smart card would contain tamper-resistant security system (for example a secure crypto-processor, secure file system, human-readable features).

Whenever, the card would be swiped, the details would be transferred onto the central system via the card reader by radio waves. It has to have a writeable memory and a microcontroller processing capability. To power the card's electronics, and to capture some of the incident electromagnetic signal, a built-in inductor, using the principle of resonant inductive coupling has to be used.

The smart card will store an encrypted digital certificate along with any other relevant or needed information about the card holder. When combined with biometrics, smart cards can provide two- or three-factor authentication. The embedded chip of a smart card usually implements some cryptographic algorithm.

\section{B. Problems that might arise}

The card in which the chip is embedded is generally plastic, and thus fairly flexible. There is a higher probability of breaking of the card, if the chip is large. Hence, a card enclosure may be provided along with the card.

The whole course of action would be time-taking. The passengers would have to arrive a lot earlier for the security checks and even the trains have to be on the platforms on time. Eventually, with practice the whole process would be speeded up, but for the initial times, it would consume a lot of time.

To prevent use of cards by any other person, who might have either borrowed it or stolen it, PIN authentication has to be incorporated.

\section{Advantages}

The prime benefit we get by introduction of these smart cards is that the security arrangements get strengthened. Ticket-less travelling is the main cause in the Indian Railways and this also results in revenue loss of the railways. Even, people get up on the train and these are responsible for theft and other crimes. With the proposed scheme, no ticket-less individual will be able to travel on the train. Even terrorist attacks (like the recent attack at Mumbai Chhatrapati Shivaji Terminal (Mumbai CST) in November 2008) can be avoided to a great extent.

\section{Conclusion}

With the above mentioned idea, the crime rates can be reduced drastically and even if crimes occur, the authorities would have necessary details of the passengers, who have booked the tickets as well as photos of the passengers, who have got into the train. The smart cards contain all the necessary details, required to track any individual.

Further work can be done to improvise the smart card, integration with many other facilities. There exists a lot of future scope once this is implemented.

\section{References}

[1]. "Security Management in Indian Railway", Report No. 14 (Railways)

[2]. Kanakia, H.; Nadhamuni,S.; Sarma, S, “A UID Numbering Scheme”, May 2010. 